\title{
Spirometry parameters in smokers and non-smokers with and without respiratory symptoms in the PURE Poland Study population
}

\author{
Katarzyna Połtyn-Zaradna', Barbara Sozańska², Alicja Basiak-Rasała', Dagmara Gaweł-Dąbrowska', \\ Maria Wołyniec' ${ }^{1}$, Andrzej Szuba ${ }^{3}$, Witold Zatoński ${ }^{4}$, Katarzyna Zatońska' \\ ${ }^{1}$ Chair and Department of Social Medicine, Wrocław Medical University, Poland \\ ${ }^{2}$ First Department and Clinic of Paediatrics, Allergology and Cardiology, Wrocław Medical University, Poland \\ ${ }^{3}$ Department of Angiology, Hypertension and Diabetology, Wroclaw Medical University, Poland \\ ${ }^{4}$ Health Promotion Foundation, Nadarzyn, Poland
}

\begin{abstract}
Aim of the study: To assess lung function and its relationship with smoking status and respiratory symptoms in the Prospective Urban and Rural Epidemiology (PURE) Poland Study population.

Material and methods: Analysis was carried in a cohort consisting of 2036 adults enrolled in the PURE Poland Study. This paper presents the results of 1217 (773 female) subjects in whom spirometry was performed and who were assessed for smoking status. We estimated the odds ratio for spirometry parameters values (forced respiratory volume in 1 second [FEV1], forced vital capacity [FVC], and FEV/FVC) using logistic regression, adjusted for sex, age, smoking status, and respiratory symptoms in the last six months. Results: Forty eight percent of participants were never smokers, 34\% were former smokers, and $17 \%$ were current smokers. Chronic obstructive pulmonary disease (COPD) was diagnosed in $1.52 \%, 1.45 \%$, and $2.39 \%$ of this population, respectively, and asthma in $4.88 \%, 1.69 \%$, and $2.87 \%$, respectively. Respiratory symptoms in the last six months were more common in current smokers than never smokers and former smokers. Conversely, spirometry parameters values (FEV1, FVC, and FEV1/FVC) did not differ significantly between the groups. In the logistic regression analyses, the strongest decrease of risk factors for FEV1/FVC, FEV1, and FVC were increasing age, and for Tiffeneau index former smoking status. Among women the decrease in FVC was more pronounced than in men (OR 3.82; 95\% CI 2.18-6.68). The presence of respiratory symptoms did not increase the risk of decline of spirometry parameters.

Conclusions: Lung function based on spirometry parameters in the surveyed PURE Poland Study population was more dependent on increasing age and female sex than on smoking status and respiratory symptoms.
\end{abstract}

KEY WORDS: spirometry, lung function, PURE, tobacco, respiratory symptoms, respiratory diseases.

ADDRESS FOR CORRESPONDENCE: Katarzyna Połtyn-Zaradna, Chair and Department of Social Medicine,

Wrocław Medical University, 44 O. Bujwida St., 50-345 Wrocław, e-mail: katarzyna.poltyn-zaradna@umed.wroc.pl

\section{INTRODUCTION}

According to the European Commission, smoking is the largest avoidable health risk factor in Europe. It causes more health problems than alcohol, high blood pressure, excessive weight or high cholesterol, and drugs combined [1]. Tobacco smoking is also a major avoidable cause of premature mortality in Poland. Almost one in three Polish men do not live to the age of 65 years, and almost half of this premature mortality can be accounted for by the much higher prevalence of smoking in Poland than in Western Europe [2]. Chronic obstructive pulmonary disease (COPD), one of the cardiorespiratory outcomes of tobacco smoking, is globally increasing in prevalence and is expected to be the third largest cause of death by 2020 [3]. 
Over the years, we have observed that smoking prevalence in Poland declined between the 1976 and 2014 from $73 \%$ to $28 \%$ among men and from $30 \%$ to $19 \%$ among women [4]. This meaningful decrease was possible, among other factors, thanks to intervention programs originating from the Polish Anti-tobacco Law of 1995 [5]. This positive trend led to the curbing smoking and, later, a fall in the rates of tobacco-related diseases. According to the GBD study [6] the annualised rates of smoking prevalence decrease between 1990 and 2015 was $1.7 \%$ among Polish men and $0.9 \%$ among Polish women, placing them among the fastest declines in the world. In Europe, only Sweden, Denmark, and the Netherlands witnessed more rapid smoking declines in males [4].

Spirometry is a basic method of monitoring many lower respiratory tract diseases. British scientists found that spirometric values predicted mortality more precisely than systolic blood pressure or body mass index, emphasising the importance of conducting spirometry in primary prevention in the general population, even among lifelong non-smokers [7]. Smoking can influence lung function measured by spirometry values, but the presence of respiratory symptoms with preserved pulmonary function among smokers is also possible [8-10].

In this paper, we investigate the prevalence of cigarette smoking and its impact on respiratory symptoms and lung function measured by spirometry parameters among adults of all ages in the population of the Prospective Urban and Rural Epidemiology (PURE) Poland cohort.

\section{MATERIAL AND METHODS}

Analysis of lung function and its relationship with smoking status and respiratory symptoms was carried out between 2007 and 2010 in a cohort enrolled in the PURE Poland Study. The PURE Poland Study baseline covered, in total, a group of 2036 adults (754 men and 1282 women), including both urban (59\%) and rural (41\%) inhabitants of Lower Silesia, a geographical region in south-west Poland. All participants were examined in accordance with the PURE project protocol, which has been described in detail elsewhere [11]. The PURE study protocol included questionnaires (family, household, individual health questionnaire, and food frequency questionnaire), anthropometric measurements, blood pressure measurements, blood draw, and spirometry. This paper presents the results of 1217 (773 female) subjects on whom spirometry was performed and who were assessed for smoking status. Spirometry was performed with a spirometer (Micro Medical Micro Gp). Prebronchodilatatory forced respiratory volume in 1 second (FEV1) and forced vital capacity (FVC) were typically measured with at least three sets of values and had two measurements differing by less than $5 \%$ as a criterion for reproducibility. The highest measurements of FEV1 and FVC were used in the analyses. FEV1, FVC, and FEV1/
FVC as a percentage of predicted value were calculated using internally derived reference values based on a subsample of healthy, asymptomatic (without wheezing, dyspnoea, chest pain or tightness, sputum, cough, and asthma) never-smokers with age and height used as covariates separately for men and women. Individuals without bronchoconstriction were defined as having a FEV1/FVC ratio equal to or greater than $70 \%$. Severity of airflow was evaluated using FEV1 as a percentage of predicted value. FEV1 equal to or greater than 70 was assumed to be correct. Diagnoses of asthma and COPD were self-reported by participants. Participants were considered ever smokers if they reported smoking at least one cigarette per day for at least one year. Ever smokers were divided into current smokers (survey question: "do you currently smoke cigarettes?") and former smokers (survey question: "did you formerly smoke cigarettes?" implicating that the participant used to smoke cigarettes but had stopped smoking before the survey).

We estimated the odds ratio for spirometry parameter values (FEV1, FVC, and FEV/FVC) using logistic regression, adjusted for sex, age, smoking status, and respiratory symptoms in the last six months. Statistical analysis was performed using Statistica 13.1 software. Statistical significance was established at $p<0.05$.

Written and informed consent was obtained from all individual participants included in the study. The study was reviewed and accepted by the Bioethics Committee of Wrocław Medical University (positive opinion no. KB-443/2006) and was therefore performed in accordance with the ethical standards laid down in an appropriate version of the 1964 Declaration of Helsinki.

\section{RESULTS}

A total of 1217 participants (968 urban and 231 rural) completed the survey questionnaire and conducted a spirometry test according to the American Thoracic Society (ATS) criteria. Sixty three percent (63.52\%) of the participants were female.

The characteristics of the population stratified by smoking status are shown in Table 1. Forty nine percent (48.81\%) of the participants indicated they were never smokers, $34 \%$ were former smokers, and $17.2 \%$ were current smokers. Mean age did not differ among these three cohorts.

There were significant differences by sex in smoking status distribution. Most female participants declared themselves as non-smokers (56.27\%), $28.33 \%$ as former-smokers, and only $15.40 \%$ as current smokers. Among men 35.91\% identified as never-smokers, 43.92\% as former-smokers, and $20.27 \%$ as current smokers.

COPD was diagnosed among $1.52 \%$ of never smokers, $1.45 \%$ of former smokers, and $2.39 \%$ of current smokers, and asthma in $4.88 \%, 1.69 \%$, and $2.87 \%$, respectively. All reported respiratory symptoms in the last six months (wheezing in the chest, cough for at least 
TABLE 1. Characteristics of the population stratified by smoking status

\begin{tabular}{|l|c|c|c|c|}
\hline Characteristic & Non-smokers & Former smokers & Current smokers & $p$-value \\
\hline Percent $(n)$ of overall population & $48.81(594)$ & $34.02(414)$ & $17.17(209)$ & \\
\hline Mean age, years & $53.46 \pm 10.12$ & $52.23 \pm 8.60$ & $52.22 \pm 8.13$ & \\
\hline Males, \% $(n)$ & $35.81(159)$ & $43.92(195)$ & $20.27(90)$ & 0.0000 \\
\hline Females, \% $(n)$ & $56.27(435)$ & $28.33(219)$ & $15.40(119)$ & \\
\hline Asthma diagnosis and/or COPD diagnosis, \% $(n)$ & $6.40(38)$ & $3.14(13)$ & $5.30(11)$ & \\
\hline FEV1\% predictive value & $99.53 \pm 21.99$ & $100.34 \pm 21.06$ & $109.58 \pm 35.78$ & 0.0000 \\
\hline FVC\% predictive value & $102.98 \pm 26.53$ & $105.79 \pm 24.57$ & $114.50 \pm 40.41$ & 0.0000 \\
\hline FEV1/FVC & $0.88 \pm 0.08$ & $0.88 \pm 0.09$ & $0.88 \pm 0.09$ & \\
\hline Respiratory symptoms in the last 6 months, \% $(n)$ & & & & $12.44(26)$ \\
\hline Wheezing in the chest & $7.58(45)$ & $7.97(33)$ & $23.02(50)$ & 0.0843 \\
\hline Cough for at least 2 weeks & $22.05(131)$ & $14.98(62)$ & $7.18(15)$ & 0.1754 \\
\hline Early morning cough with chest tightness & $4.55(27)$ & $3.86(16)$ & & \\
\hline
\end{tabular}

COPD - chronic obstructive pulmonary disease, FEV1 - forced respiratory volume in 1 second, FVC - forced vital capacity

TABLE 2. Percentage of normal and declined FEV1/FVC value by sex, age, smoking status, and respiratory symptoms in the last six months and odds ratios of the decline (logistic regression models - adjusted OR [95\% Cl])

\begin{tabular}{|c|c|c|c|c|}
\hline Characteristics of population & FEV1/FVC normal, \% ( $n)$ & FEV1/FVC declined, \% (n) & Adj. OR (95\% Cl) & $p$-value \\
\hline Females & $97.54(754)$ & $2.45(19)$ & $0.91(0.44-1.89)$ & 0.794 \\
\hline \multicolumn{5}{|l|}{ Year of birth } \\
\hline After 1960 & $98.73(312)$ & $1.27(4)$ & 1.0 (ref.) & \\
\hline Between 1940 and 1960 & $97.53(828)$ & $2.47(21)$ & $1.98(0.67-5.81)$ & 0.215 \\
\hline Before 1939 & $88.24(45)$ & $11.76(6)$ & $5.26(2.02-13.67)$ & 0.001 \\
\hline \multicolumn{5}{|l|}{ Smoking status } \\
\hline Nonsmokers & $99.0(588)$ & $1.0(6)$ & 1.00 (ref.) & \\
\hline Former smokers & $95.41(395)$ & $4.60(19)$ & $4.71(1.87-11.9)$ & 0.001 \\
\hline Current smokers & $97.13(203)$ & $2.87(6)$ & $2.90(0.92-9.08)$ & 0.068 \\
\hline \multicolumn{5}{|c|}{ Respiratory symptoms in the last six months } \\
\hline Wheezing in the chest & $95.19(99)$ & $4.81(5)$ & $2.11(0.79-5.62)$ & 0.135 \\
\hline Cough for at least 2 weeks & $97.53(237)$ & $2.47(6)$ & $0.96(0.39-2.37)$ & 0.931 \\
\hline $\begin{array}{l}\text { Early morning cough } \\
\text { with chest tightness }\end{array}$ & $94.93(55)$ & $2.17(3)$ & $2.20(0.65-7.47)$ & 0.205 \\
\hline
\end{tabular}

FEV1 - forced respiratory volume in 1 second, FVC - forced vital capacity

two weeks, and early morning cough with chest tightness) were more common among current smokers than non-smokers and former smokers. Conversely, spirometry parameters values (FEV1, FVC, and FEV1/FVC) did not differ significantly between the groups (Table 1).

In the logistic regression analyses sex was not a risk factor for the decrease of the Tiffeneau index (Table 2). The strongest risk factors for such a decrease were older age and former smoking status. Reported respiratory symptoms in the last six months were not a risk factor for FEV1/FVC decrease. For FEV1\% of predicted value and $\mathrm{FVC} \%$ of predicted value decrease the strongest risk factor was increasing age (Table 3). Among women the decrease in FVC\% of predicted value was more pronounced than in men (OR 3.82 95\%CI 2.18-6.68). The presence of respiratory symptoms did not increase the risk of decline of spirometry parameters.

\section{DISCUSSION}

Our study is one of the few papers focusing on the association between smoking status, respiratory symptoms, and lung function in the general population. We found that current respiratory symptoms reported by participants were more frequent among current smokers than former and never-smokers, but the lung function was not affected by smoking status (except for FEV1/FVC 
TABLE 3. Percentage of normal and declined FEV1\% of predicted value and FVC\% of predicted value by sex, age, smoking status, and respiratory symptoms in the last six months and odds ratios of its decline (logistic regression models - adjusted OR [95\% CI])

\begin{tabular}{|c|c|c|c|c|c|c|}
\hline $\begin{array}{l}\text { Characteristics } \\
\text { of population }\end{array}$ & $\begin{array}{c}\text { FEV1\% predicted } \\
\text { normal, \% ( } n)\end{array}$ & Adj. OR (95\% CI) & $p$-value & $\begin{array}{c}\text { FCV\% predicted } \\
\text { normal, \% (n) }\end{array}$ & $\begin{array}{l}\text { Adj. OR } \\
(95 \% \mathrm{Cl})\end{array}$ & $p$-value \\
\hline Females & $90.69(501)$ & $1.65(1.04-2.63)$ & 0.034 & $88.23(682)$ & $3.82(2.18-6.68)$ & $<0.001$ \\
\hline \multicolumn{7}{|l|}{ Year of birth } \\
\hline After 1960 & $96.84(306)$ & 1.00 (ref.) & & $95.57(302)$ & 1.00 (ref.) & \\
\hline $\begin{array}{l}\text { Between } 1940 \text { and } \\
1960\end{array}$ & $90.69(770)$ & $3.14(1.60-6.14)$ & 0.06 & $89.87(763)$ & $2.43(1.36-4.34)$ & 0.003 \\
\hline Before 1939 & $82.35(42)$ & $2.09(0.98-4.45)$ & 0.001 & $88.24(45)$ & $1.19(0.50-2.85)$ & 0.71 \\
\hline \multicolumn{7}{|l|}{ Smoking status } \\
\hline Nonsmoking & $90.91(540)$ & 1.00 (ref.) & & $90.40(537)$ & 1.00 (ref.) & \\
\hline Former smoking & $91.30(378)$ & $0.95(0.61-1.48)$ & 0.829 & $90.82(376)$ & $0.95(0.62-1.47)$ & 0.824 \\
\hline Current & $96.17(201)$ & $0.40(0.19-0.85)$ & 0.017 & $94.74(198)$ & $0.52(0.27-1.02)$ & 0.056 \\
\hline \multicolumn{7}{|c|}{ Respiratory symptoms in the last 6 months } \\
\hline $\begin{array}{l}\text { Wheezing in the } \\
\text { chest }\end{array}$ & $93.27(97)$ & $0.81(0.37-1.80)$ & 0.605 & $91.35(95)$ & $0.99(0.49-2.03)$ & 0.983 \\
\hline $\begin{array}{l}\text { Cough for at least } 2 \\
\text { weeks }\end{array}$ & $93.00(226)$ & $0.83(0.48-1.43)$ & 0.499 & $92.18(224)$ & $0.86(0.52-1.45)$ & 0.582 \\
\hline $\begin{array}{l}\text { Early morning } \\
\text { cough with chest } \\
\text { tightness }\end{array}$ & $91.38(53)$ & $1.08(0.42-2.77)$ & 0.871 & $84.48(49)$ & $2.01(0.96-4.22)$ & 0.064 \\
\hline
\end{tabular}

FEV1 - forced respiratory volume in 1 second, FVC - forced vital capacity

among former smokers) or the presence of respiratory symptoms. Not surprisingly, the strongest parameters decreasing spirometry values were increasing age and female sex for $\mathrm{FVC} \%$.

Some limitations of our study should be considered. Both tobacco smoking status and respiratory symptoms were self-reported by the participants, which could have caused some underestimations. The diagnosis of COPD and asthma were based on the questionnaire responses about the doctor's diagnosis of these diseases. On the other hand, the study examined a relatively large sample forming part of the well-respected international PURE study [11].

Smoking prevalence in our cohort was lower than in previous studies in Poland, which is in line with the trend of decline of smoking in the previous years. In our findings sex was a statistically significant differentiating factor of smoking status. According to our findings, the percentage of current smokers was higher among men than women. The same tendency can be observed in other studies, both in Poland and internationally [1, 12-14]. Sex disparities in smoking prevalence, although they still exist, seem to be narrowing, especially in high-income countries, including Poland. Poland is among the countries with a particularly high rate of smoking women. In urban areas, the smoking prevalence among women has become equal to that among men, especially in younger populations [15].
According to Gupta et al., lung function (measured as FEV1 and FVC) was strongly associated with allcause mortality, including respiratory and non-respiratory causes of death even among never smokers [7]. According to data obtained within the Atherosclerosis Risk in Communities (ARIC) Study, FVC, but not airway obstruction, predicted survival in asymptomatic adults regardless of age, smoking status, occupation, or blood pressure [16]. In our study FVC values did not differ depending on smoking status but were clearly lower in elderly people and lower among woman than men. In our study COPD was more prevalent among smokers, which is consistent with findings in literature, i.e. the Rotterdam Study [17]. However, the number of COPD diagnoses in our population was small, so the observation should be treated with caution. Some COPD diagnoses in never smokers can be the result of the presence of other environmental risk factors, besides tobacco smoking [17]. It is estimated that $25-45 \%$ of patients with COPD have never smoked [18]. According to Hancox et al. [19], both tobacco smoking and childhood-persistent asthma were associated with lower FEV1/FVC ratios, but there was no evidence that tobacco smoking had a greater effect on lung function than asthma.

In our study, FEV1/FVC decline was most prevalent among former smokers, contrary to the results obtained in other studies $[20,21]$, in which quitting smoking was 
associated with improved lung function. On the other hand, smoking cessation can be associated with weight gain, and increased body mass index (BMI) was associated with lower lung function [22], but we can only speculate that this phenomenon partially explains our observation. The other underlying mechanism may be the "healthy smoker effect" - the situation in which smokers, who experience adverse symptoms like cough, wheezing in the chest, or chest tightness while smoking, are more likely to give up smoking than smokers, who do not experience any symptoms related to lung function [23]. According to Kohansal et al., participants who quit smoking after the age of 40 years were characterised by declined FEV1 in comparison to never smokers and participants who quit earlier, but not significantly different from current smokers [21]. In our study we did not precisely determine when smoking cessation occurred. In our study, respiratory symptoms like wheezing in the chest, cough for at least two weeks, and early morning cough with chest tightness were more frequent among current smokers than former and non-smokers, but the lung function was not affected by smoking status or the presence of respiratory symptoms. The evidence for the presence of respiratory symptoms with normal FEV1 in smokers was recently discussed by Rodrigues-Roisin et al. [9], who concluded that as the decline in lung function is not always present among smokers, a better understanding of the biological mechanisms underlying symptoms in smokers with intact FEV1/FVC is needed to improve the ability to treat respiratory symptoms that occur before the development of COPD. For example, in an urban population-based study, two groups of current smokers with normal spirometry were randomly selected and followed over four years. In the group with normal diffusing capacity of the lung for carbon monoxide (DLCO), only $3 \%$ of subjects developed significant reductions in FEV1/FVC and DLCO. In the subset with low DLCO at baseline, 22\% developed COPD. There were no respiratory clinical or radiographic differences between these two groups [24]. In our study we did not conduct additional tests of lung function, thus we were not able to identify the potential risk group of future COPD incidents in our population. In another recently published survey from the Subpopulations and Intermediate Outcome Measures in COPD Study cohort [10], ever- or former smokers and never smokers with normal FEV1 were studied. Chronic respiratory symptoms were observed in $50 \%$ of smokers. In this study the use of the COPD Assessment Test (CAT), a questionnaire designed for COPD, provided a broader assessment of symptomatic burden than just respiratory symptoms. Compared with asymptomatic current or former smokers and never smokers, symptomatic smokers were younger and more likely to be current smokers. There were no differences in the spectrum of symptoms between symptomatic smokers with normal FEV1 and patients in early stages of COPD. There are also some limitations of our study to consider. The device used in the survey did not allow us to achieve the whole range of spirometry parameters (e.g. time to PEF, BEV, and EOFE).

\section{CONCLUSIONS}

Lung function based on spirometry parameters in the surveyed PURE Poland study cohort had a stronger correlation with increased age and female sex, rather than with smoking status or respiratory symptoms. Respiratory symptoms were more frequent in current smokers. Such symptoms may come before airflow limitation; thus, the study suggests that the strategy of early diagnosis and management should give special attention and priority to symptoms, not spirometry values.

\section{ACKNOWLEDGEMENTS}

Initial results of this paper were presented in the form of an abstract at the World Congress of Cardiology in Dubai 2018.

\section{FUNDING}

The main PURE study and its components are funded by the Population Health Research Institute, the Canadian Institutes of Health Research, Heart and Stroke Foundation of Ontario, and through unrestricted grants from several pharmaceutical companies, Poland sub-study: Polish Ministry of Science and Higher Education (grant no. 290/W-PURE/2008/0), Wroclaw Medical University. Additionally, presented research results, were realized within the framework of the topic: "Postawy wobec palenia tytoniu i picia alkoholu wśród mieszkańców Wrocławia i okolic uczestniczących w badaniu PURE (Prospektywne Badanie Epidemiologiczna Ludności Miejskiej i Wiejskiej" [Attitudes toward tobacco smoking and consumption of alcohol of inhabitants of Wrocław and its whereabouts, included in Prospective Urban and Rural Epidemiology (PURE) study] as per records in SIMPLE system number ST.C 300.16.078. We declare that funding body had no role in the design of the study, collection, analysis, or interpretation of data and no role in writing the manuscript in this section.

\section{DISCLOSURE}

The authors report no conflict of interest.

\section{References}

1. European Commision. Special Eurobarometer 458: Attitudes of Europeans towards tobacco and electronic cigarettes. European Union, 2017. Available from: ec.europa.eu (accessed: 3 December 2018).

2. Zatoński W, Zatoński M, Przewoźniak K. Health improvement in Poland is contingent on continued extensive tobacco control measures. Ann Agric Environ Med 2013; 20 (2): 405-411. 
3. Global Initiative for Chronic Obstructive Lung Disease. Global Strategy for the Diagnosis, Management, and Prevention of Chronic Obstructive Pulmonary Disease (2018 Report). Available from: www.goldcopd.org (accessed: 14 December 2018).

4. Zatoński WA, Zatoński M, Janik-Koncewicz K, et al. Hundred years of cigarette smoking in Poland: three phases of the tobacco epidemic. J Health Inequal 2017; 3 (2): 118-122.

5. Ustawa z dnia 9 listopada 1995 r. o ochronie zdrowia przed następstwami używania tytoniu i wyrobów tytoniowych [Journal of Law of the Republic of Poland; Act of 9 November 1995 on health protection against the effects of tobacco and tobacco products] (Dz.U. z 1996 r. Nr 10 poz. 55).

6. GBD 2015 Tobacco Collaborators. Smoking prevalence and attributable disease burden in 195 countries and territories, 1990-2015: a systematic analysis from the Global Burden of Disease Study 2015. Lancet 2017; 389 (10082): 1885-1906.

7. Gupta RP, Strachan DP. Ventilatory function as a predictor of mortality in lifelong non-smokers: Evidence from large British cohort studies. BMJ Open 2017; 7 (7): e015381.

8. Tommola M, Ilmarinen P, Tuomisto LE, et al. The effect of smoking on lung function: a clinical study of adult-onset asthma. Eur Respir J 2016; 48 (5): 1298-1306.

9. Rodriguez-Roisin R, Han MK, Vestbo J, et al. Chronic respiratory symptoms with normal spirometry. A reliable clinical entity? Am J Respir Crit Care Med 2017; 195 (1): 17-22.

10. Woodruff PG, Barr RG, Bleecker E, et al. Clinical significance of symptoms in smokers with preserved pulmonary function. N Engl J Med 2016; 374 (19): 1811-1821.

11. Teo K, Chow CK, Vaz M, et al. The Prospective Urban Rural Epidemiology (PURE) study: Examining the impact of societal influences on chronic noncommunicable diseases in low-, middle-, and high-income countries. Am Heart J 2009; 158 (1): 1-7.e1.

12. Sozańska B, Pearce N, Błaszczyk M, et al. Changes in the prevalence of cigarette smoking and quitting smoking determinants in adult inhabitants of rural areas in Poland between 2003 and 2012. Public Health 2016; 141: 178-184.

13. Polakowska M, Kaleta D, Piotrowski W, et al. Tobacco smoking in Poland in the years from 2003 to 2014. Multi-centre National Population Health Examination Survey (WOBASZ). Polish Arch Intern Med 2017; 127 (2): 91-99.

14. Ministry of Health. Global Adult Tobacco Survey Poland 20092010. Available from: https://www.who.int/tobacco/surveillance/en_tfi_gats_poland_report_2010.pdf (accessed: 17 July 2017).

15. Połtyn-Zaradna K, Basiak A, Zatońska K, et al. Prevalence of tobacco smoking among participants of PURE Poland study. J Health Inequal 2016; 2 (2): 142-147.

16. Burney PGJ, Hooper R. Forced vital capacity, airway obstruction and survival in a general population sample from the USA. Thorax 2011; 66 (1): 49-54.
17. Terzikhan N, Verhamme KMC, Hofman A, et al. Prevalence and incidence of COPD in smokers and non-smokers: the Rotterdam Study. Eur J Epidemiol 2016; 31 (8): 785-792.

18. Salvi SS, Barnes PJ. Chronic obstructive pulmonary disease in non-smokers. Lancet 2009; 374 (9691): 733-743.

19. Hancox RJ, Gray AR, Poulton R, Sears MR. The effect of cigarette smoking on lung function in young adults with asthma. Am J Respir Crit Care Med 2016; 194 (3): 276-284.

20. van Oostrom SH, Engelfriet PM, Monique Verschuren WM, et al. Aging-related trajectories of lung function in the general population-The Doetinchem Cohort Study. PLoS One 2018; 13 (5): $\mathrm{e} 0197250$.

21. Kohansal R, Martinez-Camblor P, Agustí A, et al. The natural history of chronic airflow obstruction revisited: an analysis of the Framingham Offspring Cohort. Am J Respir Crit Care Med 2009; 180 (1): 3-10.

22. Choe EK, Kang HY, Lee Y, et al. The longitudinal association between changes in lung function and changes in abdominal visceral obesity in Korean non-smokers. PLoS One; 2018; 13 (2): $\mathrm{e} 0193516$.

23. Becklake MR, Lalloo U. The 'healthy smoker': a phenomenon of health selection? Respiration 1990; 57 (3): 137-144.

24. Harvey B-G, Strulovici-Barel Y, Kaner RJ, et al. Risk of COPD with obstruction in active smokers with normal spirometry and reduced diffusion capacity. Eur Respir J 2015; 46 (6): 15891597.

\section{AUTHORS' CONTRIBUTRIONS}

$\mathrm{KPZ}, \mathrm{BS}$ and $\mathrm{ABR}$ analyzed and interpreted data, wrote the manuscript and revised it. DGD wrote and revised the manuscript. MW collected and analyzed data. AS and WZ contributed to concept and design and revised the manuscript. KZ contributed to concept and design, wrote and revised the manuscript. All authors have given final approval of the version to be published. 